\title{
Interpretation of Velocity Profiles of the Mantle
}

\author{
L. Burdick AND Don L. ANDERson \\ Seismological Laboratory, California Institute of Technology, Pasadena, California 91109
}

\begin{abstract}
The purpose of this note is to demonstrate that recent $V_{p}$ and $V_{s}$ profiles are consistent with finite strain extrapolations of reasonable mineralogies. The difference in the size of the discontinuities in the $V_{p}$ and $V_{s}$ profiles is due to the relative pressure insensitivity of shear velocity in spinel structures. Most of the structure in the upper mantle can be attributed to the collapse of forsterite rich olivine to the $\beta$ spinel and then the $\gamma$ spinel structures. The $640-\mathrm{km}$ discontinuity on the basis of recent work appears to be due to the disproportionation of $\gamma$ spinel to a mixture of magnesiowustite $(\mathrm{Mg}, \mathrm{Fe}) \mathrm{O}$ and stishovite. The present results indicate that this postspinel phase in the lower mantle is enriched in $\mathrm{SiO}_{2}$ relative to the upper mantle. The $640-\mathrm{km}$ discontinuity is therefore a chemical as well as a phase boundary.
\end{abstract}

Helmberger and Engen [1974] have recently determined a shear velocity structure (SHR14) for the upper mantle that satisfies both travel time and wave form data. It has many features in common with the compressional velocity models, derived by similar techniques by Helmberger and Wiggins [1971] and Wiggins and Helmberger [1973]. Although it is more detailed, it is in general agreement with other recent upper-mantle shear velocity models. It has a low-velocity zone and two abrupt velocity increases near 400 and $600 \mathrm{~km}$. In these respects it is similar to the shear velocity models of Anderson and Toksöz [1963], Anderson and Julian [1969], Ibriham and Nuttli [1967], Nuttli [1969], and Jordan and Anderson [1974].

The main new feature of the models derived by Helmberger and his colleagues is a broad discontinuity near $500 \mathrm{~km}$; this appears in both the $V_{p}$ and the $V_{s}$ profiles. The main differences between the $V_{s}$ and $V_{p}$ profiles are the relatively slow increase of $V_{s}$ between the discontinuities and the size of the $V_{s}$ jump at $400 \mathrm{~km}$, which is smaller than the corresponding increase in $V_{p}$ across this transition region. Whitcomb and Anderson [1970] had suggested a discontinuity near $500 \mathrm{~km}$ based on precursors to the $P^{\prime} P^{\prime}$ phase reflections under oceanic areas. Simpson [1973] also found evidence for such a feature in Australia. It therefore seems to be a real and widespread feature of the mantle. The smallness of the $S$ velocity jump at $400 \mathrm{~km}$ also appears to be real on the basis of the wave form study. A large amount of effort has gone into developing theoretical techniques and collecting laboratory data to explain the observed compressional velocity profile in terms of mineralogical models of the upper mantle. Our purpose is to show that the new shear velocity profile, in particular its apparent differences from the compressional velocity profiles, can be explained in terms of a simple but reasonable mineralogical model. An explanation of the smallness of the $400-\mathrm{km}$ discontinuity for shear waves is one immediate problem. To this end we have computed $P$ and $S$ profiles that fit the seismic data, using laboratory data on mantle minerals and finite strain theory. The calculated zero-pressure parameters of the various regions of the mantle are compared with ultrasonic data on a variety of minerals.

\section{Calculation of Wave Velocities}

The techniques for computing seismic velocities in a selfcompressed solid were developed by Birch [1939] and refined by Sammis et al. [1970]. Application to earlier seismic models has been performed by Anderson et al. [1971] and Anderson

Copyright (C) 1975 by the American Geophysical Union. and Jordan [1970]. The expressions for $V_{p}$ and $V_{s}$ can be written

$$
\begin{aligned}
& V_{p}^{2}(T, P)=V_{p 0}{ }^{2}(T)(1-2 \epsilon) \\
& \cdot\left[1-2 \epsilon\left(3 K_{0}(T) D_{p 0}(T)-1\right)\right] \\
& V_{s}^{2}(T, P)=V_{s 0}{ }^{2}(T)(1-2 \epsilon) \\
& \cdot\left[1-2 \epsilon\left(3 K_{0}(T) D_{s 0}(T)-1\right)\right] \\
& V_{\phi}^{2}(T, P)=V_{p}{ }^{2}(T, P)-(4 / 3) V_{s}{ }^{2}(T, P) \\
& =\phi(T, P)
\end{aligned}
$$

$$
D_{\eta 0}=\left.\left(\frac{\partial \ln V_{\eta}}{\partial P}\right)_{T}\right|_{P=0}
$$

$\eta=p, s$, or $\phi, \epsilon$ is the hydrostatic strain, and the subscript zero implies the value at zero pressure. In the corresponding equations given by Sammis et al. [1970] there is a misprint where $\rho$ was written as $\rho_{0}$. The strain can be calculated from the pressure $P$ by using the Birch equation of state:

$$
P=-3 K_{0}(T)(1-2 \epsilon)^{5 / 2}(1+2 \epsilon \xi)
$$

Here $K_{0}$ is either the isothermal or adiabatic bulk modulus at zero pressure, depending upon the conditions. Since the two constants are nearly the same for most mantle minerals [Anderson et al., 1968], we have assumed that they are equal. The $\xi$ satisfies the equation

$$
\xi=(9 / 4)-(3 / 2) \rho_{0}\left[V_{p 0}^{2} D_{p 0}-(4 / 3) V_{s 0}^{2} D_{s 0}\right]
$$

where $\rho_{0}$ represents the zero pressure density.

For the upper mantle we have used the approach of Gilvarry [1957] and assumed that $K_{0}, \rho_{0}$, and $\mu_{0}$ can be replaced by their temperature dependent equivalents. We take

$$
\begin{aligned}
(\partial \ln \rho / \partial T)_{P} & =-\alpha(T, P) \\
(\partial \ln K / \partial \ln \rho)_{P} & =c \\
(\partial \ln \mu / \partial \ln \rho)_{P} & =b
\end{aligned}
$$

where $c$ and $b$ are quantities that can be related to the interatomic potential [Anderson, 1967]. We assume that their dependence on temperature and pressure is small. Integrating yields

$$
\begin{gathered}
\rho_{0}\left(T_{F}\right)=\rho_{0}\left(T_{I}\right) \exp \left(-\int_{T_{I}}^{T_{F}} \alpha d T\right) \\
K_{0}\left(T_{F}\right)=K_{0}\left(T_{I}\right) \exp \left(-c \int_{T_{I}}^{T_{F}} \alpha d T\right)
\end{gathered}
$$




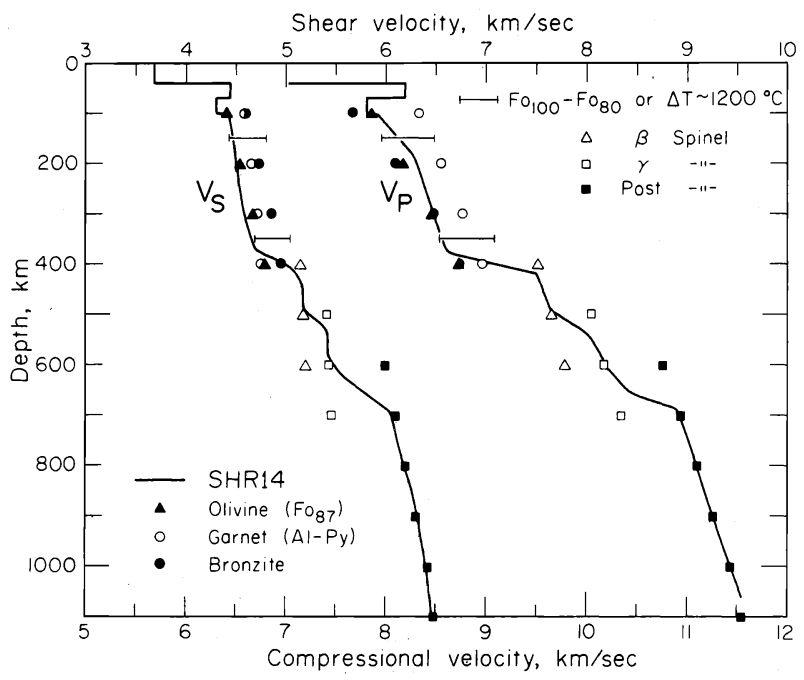

Fig. 1. Velocity model SHR 14 [Helmberger and Engen, 1974]. Also shown are finite strain predictions for olivine, garnet, and bronzite $(100-400 \mathrm{~km}), \beta$ spinel and $\gamma$ spinel $(400-600 \mathrm{~km})$, and finite strain fits to the upper part of the lower mantle, the postspinel region.

$$
\mu_{0}\left(T_{F}\right)=\mu_{0}\left(T_{I}\right) \exp \left(-b \cdot \int_{T_{I}}^{T_{F}} \alpha d T\right)
$$

where $T_{I}$ and $T_{F}$ are the initial and final temperatures. The temperature dependence of $D_{p 0}$ and $D_{s 0}$ follows from the definitions of the seismic velocities in terms of $K_{0}, \mu_{0}$, and $\rho_{0}$ and the thermodynamic relation

$$
\begin{aligned}
\int_{T_{I}}^{T_{F}}\left(\frac{\partial \alpha}{\partial P}\right)_{T} d T= & -\int_{T_{I}}^{T_{F}}\left(\frac{\partial K^{-1}}{\partial T}\right)_{P} d T \\
= & \frac{1}{K\left(T_{I}\right)}-\frac{1}{K\left(T_{F}\right)} \\
D_{\phi 0}\left(T_{F}\right)= & D_{\phi 0}\left(T_{I}\right) \\
& +\left(\frac{c-1}{2}\right)\left(\frac{1}{K\left(T_{F}\right)}-\frac{1}{K\left(T_{I}\right)}\right) \\
D_{s 0}\left(T_{F}\right)= & D_{s 0}\left(T_{I}\right) \\
& +\left(\frac{b-1}{2}\right)\left(\frac{1}{K\left(T_{F}\right)}-\frac{1}{K\left(T_{I}\right)}\right) \\
D_{p 0}\left(T_{F}\right)= & \left(\frac{V_{\phi}\left(T_{F}\right)}{V_{p}\left(T_{F}\right)}\right)^{2} D_{\phi 0}\left(T_{F}\right) \\
& +\frac{4}{3}\left(\frac{V_{s}\left(T_{F}\right)}{V_{p}\left(T_{F}\right)}\right)^{2} D_{s 0}\left(T_{F}\right)
\end{aligned}
$$

For purposes of evaluating the integrals in (9), (10), and (11) it is assumed that

$$
\int_{T_{I}}^{T_{F}} \alpha d T \sim \alpha_{0}\left(T_{I}\right)\left(T_{F}-T_{I}\right)
$$

For the lower mantle we followed Jordan and Anderson [1974] in assuming that conditions are adiabatic. Since the Birch equation of state transforms isomorphically from the isothermal to the adiabatic case [Clark, 1962], (1)-(4) can be applied directly with the stipulation that all derivatives are to be taken isentropically. Also by using the measured velocity profiles and assuming a pressure-depth curve we have determined the logarithmic pressure derivative of the lower-mantle velocities at depth. The velocities can be expressed in terms of the high-pressure rather than the zero-pressure derivatives by differentiating (1) and (2) with respect to strain to obtain

$$
\begin{aligned}
3 K_{0} D_{p} \frac{\phi}{\phi_{0}} & =\frac{1}{(1-2 \epsilon)^{3 / 2}} \\
& +\frac{\left(3 K_{0} D_{p 0}-1\right)}{\left[1-2 \epsilon\left(3 K_{0} D_{p 0}-1\right)\right](1-2 \epsilon)^{1 / 2}} \\
3 K_{0} D_{s} \frac{\phi}{\phi_{0}} & =\frac{1}{(1-2 \epsilon)^{3 / 2}} \\
& +\frac{\left(3 K_{0} D_{s}-1\right)}{\left[1-2 \epsilon\left(3 K_{0} D_{s 0}-1\right)\right](1-2 \epsilon)^{1 / 2}}
\end{aligned}
$$

Solving for $D_{p 0}$ and $D_{s 0}$ and substituting back in (1) and (2) yield

$$
\begin{aligned}
& V_{p}{ }^{2}=V_{p 0}{ }^{2} \frac{(1-2 \epsilon)^{2}}{1-2 \epsilon\left[2-3 K_{0} D_{p}\left(\phi / \phi_{0}\right)(1-2 \epsilon)^{3 / 2}\right]} \\
& V_{s}{ }^{2}=V_{s 0}{ }^{2} \frac{(1-2 \epsilon)^{2}}{1-2 \epsilon\left[2-3 K_{0} D_{s}\left(\phi / \phi_{0}\right)(1-2 \epsilon)^{3 / 2}\right]}
\end{aligned}
$$

\section{UPPER MANTLE}

Realistic multicomponent models of the mantle have been considered by Anderson [1970], Ringwood [1972], and Ahrens [1973]. They have suggested that it is the collapse of the magnesium rich olivine component to a $\beta$ spinel structure near $400 \mathrm{~km}$, to a $\gamma$ spinel structure near $500 \mathrm{~km}$, and to a postspinel phase near $600 \mathrm{~km}$ that is responsible for the velocity discontinuities at the corresponding depths. Since we are not attempting to resolve the fine details of the mineralogy, we have adopted for this study a pure olivine mantle. From this simplified model the zero-pressure parameters of the various regions have been computed and compared with ultrasonic data.

To compute the velocities for the region between 100 and $400 \mathrm{~km}$, we have used the temperature dependent finite strain equations, the geotherm proposed by Swift [1969], the pressure-depth curve of Jordan and Anderson [1974], and the elastic constant data from Anderson et al. [1968], Graham [1970], Sammis et al. [1970], and Frisillo and Buljan [1972]. For this geotherm, olivine $\mathrm{Fo}_{83} \mathrm{Fa}_{17}$ has velocities very near those observed, as is shown in Figure 1, but the theoretical velocities of bronzite and Al-Py garnet fall close enough that pyroxene and garnet can be mixed in with no serious consequence to the theoretical results. The bars indicate the range of velocity in olivine as the $\mathrm{Fe}_{2} \mathrm{SiO}_{4}$ varies from 0 to $20 \% M$ or alternatively as temperature varies by roughly $1200^{\circ}$. This illustrates the

TABLE 1. Observed Versus Predicted Densities for the Earth

\begin{tabular}{ccc}
\hline Depth, $\mathrm{km}$ & $\begin{array}{c}\text { Model B1 Density, } \\
\mathrm{g} / \mathrm{cm}^{3}\end{array}$ & $\begin{array}{c}\text { Theoretical Density, } \\
\mathrm{g} / \mathrm{cm}^{3}\end{array}$ \\
\hline 100 & 3.32 & 3.45 \\
200 & 3.37 & 3.53 \\
300 & 3.47 & 3.61 \\
400 & 3.57 & 3.68 \\
500 & 3.87 & 3.95 \\
600 & 3.97 & 4.05 \\
700 & 4.25 & 4.39 \\
800 & 4.46 & 4.46 \\
900 & 4.52 & 4.53 \\
1000 & 4.58 & 4.59 \\
\hline
\end{tabular}


degree of trade off between the uncertainty in these parameters. Table 1 compares the computed densities of olivine $\left(\mathrm{Fo}_{83}\right)$ with the appropriate values from the Jordan and Anderson [1974] free oscillation model B1. Although olivine of this composition has appropriate velocities, it is too dense by about $1.5 \mathrm{~g} / \mathrm{cm}^{3}$. This density indicates that a more realistic upper-mantle model would either contain a lower-density material with olivinelike velocities, for instance, pyroxene, or have a lower iron content and a higher temperature.

\section{Transition Region}

The set of equations (1)-(16) require 10 input parameters to compute a velocity-depth profile. If temperature and pressure are assumed to be known, $D_{p 0}, D_{s 0}, K_{0}, \mu_{0}, \rho_{0}$, and the temperature derivatives are left. Since none of these parameters are available for mantle spinel $\left((\mathrm{Mg}, \mathrm{Fe})_{2} \mathrm{SiO}_{4}\right)$, we cannot simply substitute in the equations, as we did before. In order to test the olivine- $\beta$ spinel- $\gamma$ spinel model for the transition region we have taken the approach of assuming that the pressure and temperature derivatives of the spinels are approximately the same as those of $\mathrm{MgAl}_{2} \mathrm{O}_{4}$ spinel and of assuming a density jump of $7.5 \%$ for the $\alpha-\beta$ transition and $10 \%$ for the $\alpha-\gamma$ transition [Ringwood, 1972], and we have found, by trial and error, values of $K_{0}\left(T_{I}\right)$ and $\mu_{0}\left(T_{I}\right)$ that satisfy the velocity profiles. Finally, the computed zeropressure properties of the mantle spinels have been plotted on Birch diagrams in Figures 2 and 3. The results indicate reasonable compatibility with the assumption of chemical homogeneity for the upper mantle. The light solid curves were

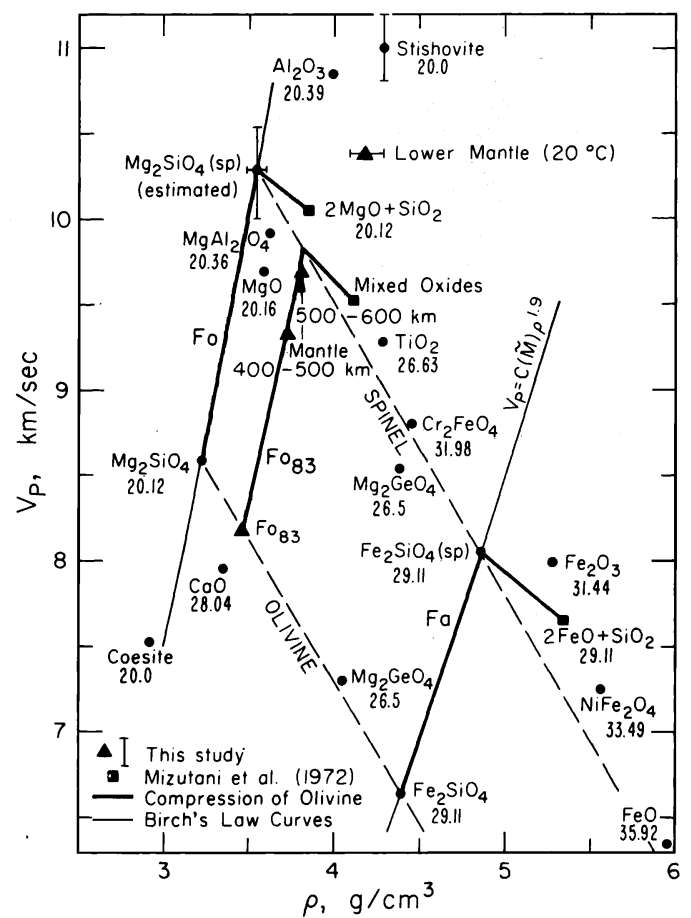

Fig. 2. Inferred zero-pressure $V_{p}$ and $\rho$ for olivine $\left(\mathrm{Fo}_{83}\right), \beta$ spinel, and $\gamma$ spinel regions of mantle (solid triangles) that are required to match the seismic profiles. The point (solid triangle) for the lower mantle is based on finite strain extrapolation (this study) combined with B1 densities. Note that the upper-mantle points satisfy a single power law relationship between $V_{p}$ and $\rho$, suggesting uniform composition in this region. The power law relationship does not hold for breakdown to oxides. The lower mantle is apparently neither a Birch's law extension of the upper mantle nor mixed oxides in olivine proportions. The figure is modified from Anderson et al. [1971]. The stishovite data are from Mizutani et al. [1972].

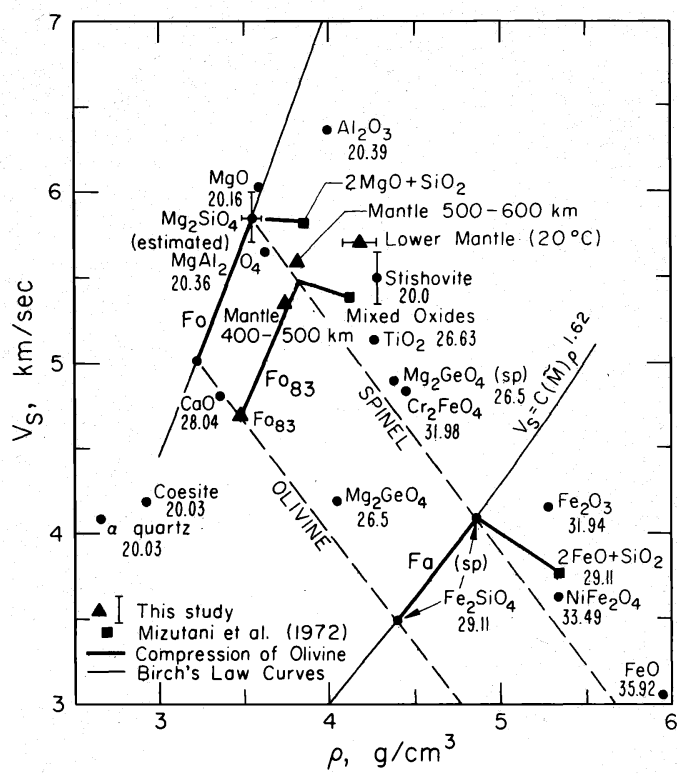

Fig. 3. Same as Figure 2 but for $V_{s}$ versus $\rho$.

computed from the power law formulation of Birch's law [Anderson, 1967]:

$$
V=C(\bar{M}) \rho^{\lambda}
$$

where $C(\bar{M})$ is a constant depending on mean atomic weight. We have assumed that the measured values of $\lambda_{p}=1.9$ and $\lambda_{s}$ $=1.6$ [Liebermann and Ringwood, 1973] for $\mathrm{Fe}_{2} \mathrm{SiO}_{4}$ are not strong functions of iron content. Judging from the variation of the $\lambda$ in analog structures, we should find this to be correct to within \pm 0.25 . The estimated density jumps should be correct to within $2 \%$ or so.

The consistency of the computed results with Birch's law indicates that the small $S$ relative to $P$ velocity jump at $400 \mathrm{~km}$ and the properties across the $500-\mathrm{km}$ discontinuity meet the requirements of both empirical and theoretical equations of state of a solid under pressure. From the computed spinel velocities in Figure 1 it is apparent that the shear velocity of spinels is not as strong a function of pressure as the compressional velocity, which is the reason that the $400-\mathrm{km}$ discontinuity (for $V_{s}$ ) is small. The $P$ velocity gradients in this region do not correspond with the observations as well as the $S$ velocity gradients do, possibly an effect of phase mixing; however, D. V. Helmberger (personal communication, 1974) has indicated that the resolution of the slope is poorer than the discrepancy between theoretical and observed slopes.

\section{LOWER MANTLE}

If the earth's lower mantle is adiabatic, it should be possible to determine its zero-pressure, high-temperature properties more reliably than those of the transition region. Since the temperature derivatives are not needed in the adiabatic case and since the pressure derivatives can be determined from the velocity profile, the only parameters that still need to be specified are $K_{0}, \mu_{0}$, and $\rho_{0}$. When one has been chosen, the other two can be determined by requiring that (12) and (13) satisfy the observed velocities at the depth where the pressure derivatives were computed. Complete profiles then follow from (1)-(5). Anderson and Jordan [1970] have estimated that the zero-pressure, adiabatic temperature density of the lower mantle is between 3.9 and $4.1 \mathrm{~g} / \mathrm{cm}^{3}$. If we assume values for $D_{p}$ and $D_{s}$ of $0.290 \cdot 10^{-12}$ and $0.329 \cdot 10^{-12} \mathrm{~cm}^{2} / \mathrm{dyn}$ at 900 
TABLE 2. Estimated Zero-Pressure Values for the Earth's Mantle

\begin{tabular}{lcccccc}
\hline Material & $\rho_{0}$ & $V_{p 0}$ & $V_{s 0}$ & $D_{p 0}$ & $D_{s 0}$ & $\xi$ \\
\hline Olivine Fo $\mathrm{Fo}_{\mathbf{s}}$ & 3.46 & 8.19 & 4.69 & 1.16 & 0.769 & -0.24 \\
$400-500 \mathrm{~km}$ & 3.72 & 9.34 & 5.36 & $0.494 \dagger$ & $0.0762 \dagger$ & $-0.21 \dagger$ \\
$500-600 \mathrm{~km}$ & 3.81 & 9.70 & 5.60 & $0.494 \dagger$ & $0.0762 \dagger$ & $-0.21 \dagger$ \\
Lower mantle & $3.9^{*}$ & 9.94 & 5.47 & 0.435 & 0.509 & 0.92 \\
(uppermost) & $4.1^{*}$ & 9.95 & 5.47 & 0.434 & 0.508 & 0.85 \\
& 4.08 & 10.37 & 5.71 & $\ldots$ & $\ldots$ & $\ldots$ \\
& 4.28 & 10.39 & 5.71 & $\ldots$ & $\ldots$ & $\ldots$ \\
\hline
\end{tabular}

* Adiabatic temperature.

$\uparrow$ Adopted.

$\mathrm{km}$, the extremal values of density lead to the zero-pressure properties listed in Table 2, which lead to the profiles in Figure 1. Changes in density of this order lead to almost identical zero-pressure velocities. Therefore the density is not well determined, but the zero-pressure velocities are rather tightly constrained. Accordingly, the lower mantle plots as a horizontal line segment on the Birch diagrams (Figures 1 and 2). If the average Anderson-Jordan $\rho_{0}$ value of $4.0 \mathrm{~g} / \mathrm{cm}^{3}$ at $1600^{\circ} \mathrm{C}$ is assumed, we obtain the theoretical densities in Table 1 . They compare remarkably well with $\mathrm{B} 1$ densities. This also shows that the appropriate $\rho_{0}$ is somewhere close to the midpoint of the density range that we have considered. The velocities were corrected to room temperature from the adiabatic temperature of approximately $1600^{\circ} \mathrm{C}$ by using the Clark and Ringwood [1964] estimate of a 4-5\% density change, the Anderson and Jordan [1970] estimate that $(\partial \ln \phi / \partial \ln \rho)_{P} \sim 2$, and the assumption of constant Poisson's ratio.

Recent static high-pressure results strongly indicate that the postspinel phase is a simple mixture of the oxides $(\mathrm{Fe}, \mathrm{Mg}) \mathrm{O}$ and $\mathrm{SiO}_{2}$ (stishovite) [Ming and Bassett, 1974; Kumazawa et al., 1974]. The heavy line that departs sharply from the Birch curve in Figures 2 and 3 shows the path that olivine follows as it breaks down into oxides [Mizutani et al., 1972]. On the $\rho-V_{p}$ plot the lower mantle has a velocity about $0.9 \mathrm{~km} / \mathrm{s}$ higher than that predicted by mixed oxides of upper-mantle composition. Stishovite has a higher velocity than either the lower mantle or $\mathrm{MgO}$. On the $\rho-V_{s}$ plot the lower mantle is about 0.3 $\mathrm{km} / \mathrm{s}$ higher in velocity than the predicted mixed oxides, and stishovite has a velocity lower than $\mathrm{MgO}$ and slightly lower than the lower mantle itself. The $V_{p}$ results indicate that the lower mantle is enriched in $\mathrm{SiO}_{2}$ with respect to the upper mantle; if the lower mantle $V_{s}$ point is taken at face value, it indicates the addition of some other higher-velocity substance such as $\mathrm{MgO}$ or low-spin iron. The addition of $\mathrm{MgO}$ would decrease the density and can be ruled out. Therefore if the lower mantle is a simple mixture of oxides, it is enriched in $\mathrm{SiO}_{2}$ relative to the upper mantle and requires a phase, possibly low-spin $\mathrm{FeO}$, that increases the shear velocity.

\section{Discussion}

Olivine $\mathrm{Fo}_{83} \mathrm{Fa}_{17}$ has seismic velocities that satisfy the new velocity profiles above $400 \mathrm{~km}$. Other minerals such as garnet and pyroxene could be, and on the basis of petrologic data and the free oscillation densities probably are, also present in this region. The collapse of the same olivine to $\beta$ spinel and then to $\gamma$ spinel structures explains the $400-\mathrm{km}$ and $500-\mathrm{km}$ discontinuities and also satisfies Birch's law. The relatively small size of the $400-\mathrm{km}-V_{s}$ discontinuity is a manifestation of the weak pressure dependence of shear velocity in spinels. These conclusions are only weakly dependent on the assumed geotherm. The inferred iron content of the olivine can be decreased by increasing the temperature or by adding pyroxene. In either case the velocity data can be satisfied, and the upper-mantle density will be in better agreement with model B1. We have also assumed that the $D_{p 0}$ and $D_{s 0}$ of $\mathrm{MgAl}_{2} \mathrm{O}_{4}$ are appropriate for mantle spinels. With these assumptions the upper mantle appears to be chemically homogeneous.

If the finite strain relations are cast into a form in which they depend on ambient rather than zero-pressure velocity derivatives, they can be applied to the lower mantle with only one unconstrained parameter $\rho_{0}$. The resulting values of $\left(V_{p}\right)_{0}$ and $\left(V_{s}\right)_{0}$ do not vary significantly as $\rho_{0}$ varies over a reasonable range.

The inferred zero-pressure properties of the lower mantle can be compared with estimates made by Mizutani et al. [1972] for the system $2\left(\mathrm{Mg}_{(1-x)}, \mathrm{Fe}_{x}\right) \mathrm{O}+\mathrm{SiO}_{2}$ (stishovite). The parameters $\rho, V_{p}$, and $V_{s}$ are not consistent with any composition with this (olivine) stoichiometry. For example, the lowermantle $\rho_{0}$ implies $\mathrm{FeO} \sim 0.2 \mathrm{M}$, whereas $\left(V_{s}\right)_{0}$ implies $\mathrm{FeO} \sim$ $0.07 M$. The $\left(V_{p}\right)_{0}$ for the lower mantle is higher than that for any other composition in this system. This comparison suggests that more stishovite is present in the lower mantle than would result from the disproportionation of olivine to the oxides. In order to simultaneously satisfy the density, $V_{p}$, and $V_{s}$ it appears that a near-pyroxene stoichiometry $(\mathrm{Mg}, \mathrm{Fe}) \mathrm{O}+$ $\mathrm{SiO}_{2}$ with $\mathrm{Fe}^{2+}$ in the low-spin state [Gaffney and Anderson, 1973] will be required. Anderson et al. [1971] and Gaffney and Anderson [1973] also concluded that the lower mantle is enriched in $\mathrm{SiO}_{2}$ relative to the upper mantle. This would make the average mantle more chondritic than petrologic models of the upper mantle. The temperature correction applied to the lower mantle is probably of relatively low accuracy. However, even the zero-pressure, high-temperature velocities are higher than the predicted mixed oxide values. It seems quite certain therefore that the lower mantle is chemically different from the mixed oxides of olivine. If the temperature correction for $V_{s}$ has been severely overestimated, $\mathrm{SiO}_{2}$ enrichment may be the sole chemical change that is necessary to explain the observations.

The size of the velocity jumps relative to the density jumps at the $400-\mathrm{km}$ discontinuity (olivine- $\beta$ spinel) and the $500-\mathrm{km}$ discontinuity $(\beta-\gamma$ spinel) is consistent with the isochemical phase change data of Liebermann and Ringwood [1.973]. The relative jumps in velocity and density associated with the 600$\mathrm{km}$ discontinuity, however, are quite different from the shallower discontinuities and different from any of the phase changes studied by Liebermann and Ringwood [1973]. G. F. Davies (preprint, 1974) pointed out that $\Delta V / \Delta \rho$ is much smaller for the spinel-oxide phase change than for the olivinespinel phase change. Anderson [1969] had previously noted that the elastic properties of spinels were close to those of the mixed oxides. Therefore only a small jump in velocity would be expected for the spinel-postspinel phase change. Our results indicate that $\Delta V / \Delta \rho$ at $600 \mathrm{~km}$, particularly for the bulk sound 
speed $\phi$, is much greater than is inferred by Davies for isochemical collapse. All of these findings suggest that the $640-\mathrm{km}$ discontinuity is both a phase and a chemical boundary.

Acknowledgments. We are grateful to D. Helmberger and G. Engen for an advance copy of their paper. Conversations with D. Helmberger have been most helpful. This research was supported by the Advanced Research Projects Agency of the Department of Defense and was monitored by the Air Force Office of Scientific Research under contract F 44620-72-C-0078 and National Science Foundation grant GA 40752 . This paper is contribution 2506 of the Division of Geological and Planetary Sciences, California Institute of Technology, Pasadena, California.

\section{REFERENCES}

Ahrens, T. J., Petrologic properties of the upper $670 \mathrm{~km}$ of the earth's mantle, Phys. Earth Planet. Interiors, 7, 167, 1973.

Anderson, D. L., A seismic equation of state, Geophys. J. Roy. Astron. Soc., 13, 9-30, 1967.

Anderson, D. L., Bulk modulus-density systematics, J. Geophys. Res. 74, 3857-3864, 1969.

Anderson, D. L., Petrology of the mantle, Mineral. Soc. Amer. Spec. Pap. 3, 85, 1970

Anderson, D. L., and T. Jordan, The composition of the lower mantle, Phys. Earth Planet. Interiors, 3, 23, 1970.

Anderson, D. L., and B. R. Julian, Shear velocities and elastic parameters of the mantle, J. Geophys. Res., 74, 3281-3286, 1969.

Anderson D. L., and M. N. Toksöz, Surface waves on a spherical earth, 1, Upper mantle structure from Love waves, J. Geophys. Res., $68,3483-3500,1963$.

Anderson, D. L., C. Sammis, and T. Jordan, Composition and evolution of the mantle and core, Science, 171, 1103-1112, 1971.

Anderson, O. L., E. Schreiber, R. C. Liebermann, and N. Soga, Some elastic constant data on minerals relevant to geophysics, Rev. Geophys. Space Phys., 6, 491-524, 1968.

Birch, F., The variation of seismic velocities within a simplified earth model in accordance with the theory of finite strain, Bull. Seismol. Soc. Amer., 29, 463, 1939.

Clark, S. P., Jr., Research in Geochemistry, edited by P. H. Abelson, pp. 495-511, John Wiley, New York, 1962.

Clark, S. P., and A. E. Ringwood, Density distribution and constitution of the mantle. Rev. Geophys. Space Phys., 2, 35-88, 1964.

Frisillo, A. L., and S. T. Buljan, Linear thermal expansion coefficients of orthopyroxene to $1000^{\circ} \mathrm{C}, J$. Geophys. Res., 77, 7115-7117, 1972.

Gaffney, E. S., and D. L. Anderson, Effect of low-spin $\mathrm{Fe}^{2+}$ on the composition of the lower mantle, J. Geophys. Res., 78, 7005-7014, 1973.
Gilvarry, J. J., Temperature dependent equations of state of solids, $J$. Appl. Phys., 28, 1253-1261, 1957.

Graham, E. K., Elasticity and composition of the upper mantle, Geophys. J. Roy. Astron. Soc., 20, 285-302, 1970.

Helmberger, D. V., and G. R. Engen, Upper mantle shear structure, $J$. Geophys. Res., 79, 4017-4028, 1974

Helmberger, D. V., and R. Wiggins, Upper mantle structure of the midwestern United States, J. Geophys. Res., 76, 3229-3245, 1971.

Ibriham, A. K., and O. W. Nuttli, Travel time curves and upper.mantle structure from long period $S$ waves, Bull. Seismol. Soc. Amer., 57, 1063-1092, 1967.

Jordan, T. H., and D. L. Anderson, Earth structure from free oscillations and travel times, Geophys. J. Roy. Astron. Soc., 36, $411-459,1974$.

Kumazawa, M., H. Sawamoto, E. Ohtani, and K. Masaki, Post-spinel phase of forsterite and evolution of the earth's mantle, Nature, 247, 356-358, 1974.

Liebermann, R. C., and A. E. Ringwood, Birch's law and polymorphic phase transformations, J. Geophys. Res., 78, 6926-6932, 1973.

Ming, L.-C., and W. A. Bassett, The post-spinel phases in $\mathrm{Mg}_{2} \mathrm{SiO}_{4}^{-}$ $\mathrm{Fe}_{2} \mathrm{SiO}_{4}$ system up to $80 \% \mathrm{Mg}_{2} \mathrm{SiO}_{4}$ (abstract), Eos Trans. $A G U, 55$, 416-417, 1974.

Mizutani, H., Y. Hamamo, and S. Akimoto, Elastic-wave velocities of polycrystalline stishovite, J. Geophys. Res., 77, 3744-3749, 1972.

Nuttli, O. W., Travel times and amplitudes of $S$ waves from nuclear explosions in Nevada, Bull. Seismol. Soc. Amer., 59, 385-398, 1969.

Ringwood, A. E., The Nature of the Solid Earth, edited by E. C. Robertson, McGraw-Hill, New York, 1972.

Sammis, C., D. L. Anderson, and T. Jordan, Application of isotropic finite strain theory to ultrasonic and seismological data, J. Geophys. Res., 75, 4478-4480, 1970.

Simpson, D. W., $P$-wave velocity structure of the upper mantle in the Australian region, Ph.D. thesis, 350 pp., Aust. Nat. Univ., Canberra, Australia, 1973.

Swift, C. M., A magnetotelluric investigation of an electrical conductivity anomaly in the southwestern United States, Ph.D. thesis, Mass. Inst. of Technol., Cambridge, 1969.

Whitcomb, J. H., and D. L. Anderson, Reflection of $P^{\prime} P^{\prime}$ seismic waves from discontinuities in the mantle, J. Geophys. Res., 75 , 5713-5728, 1970.

Wiggins, R. A., and D. V. Helmberger, Upper mantle structure of western United States, J. Geophys. Res., 78, 1870-1880, 1973.

(Received June 27, 1974; revised September 13, 1974; accepted October 25, 1974.) 